\title{
A NOTE ON SINGULAR INTEGRALS ASSOCIATED WITH A VARIABLE SURFACE OF REVOLUTION
}

\author{
DASHAN FAN AND SHUichi SATO
}

\begin{abstract}
We prove $L^{p}$ boundedness of certain singular integral operators associated with a variable surface of revolution assuming a boundedness of related lower dimensional maximal operators. The singular integrals are defined by rough kernels satisfying certain size and cancellation conditions.
\end{abstract}

Mathematics subject classification (2000): Primary 42B20.

Keywords and phrases: singular integral, rough kernel, surface of revolution.

\section{REFERENCES}

[1] A. P. Calderó n And A. Zygmund, On singular integrals, Amer. J. Math., 78 (1956), 289-309.

[2] A. Carbery, A. Seeger, S. Wainger and J. Wright, Classes of singular integral operators along variable lines, J. Geometric Analysis, 9 (1999), 583-605.

[3] J. DuoAndikoetxea And J. L. Rubio De Francia, Maximal and singular integral operators via Fourier transform estimates, Invent. Math., 84 (1986), 541-561.

[4] D. FAN, K. GUO AND Y. PAN, A note of a rough singular integral operator, Math. Inequal. Appl., 2 (1999), 73-81.

[5] D. FAN AND Y. PAN, Singular integral operators with rough kernels supported by subvarieties, Amer. J. Math., 119 (1997), 799-839.

[6] D. FAn AND S. SATO, Remarks on Littlewood-Paley functions and singular integrals, J. Math. Soc. Japan, 54 (2002), 565-585.

[7] D. FAN AND S. SATO, Singular and fractional integrals along variable surfaces, Hokkaido Math. J., 35 (2006), 61-85.

[8] D. FAn And Q. Zheng, Maximal singular integral operators along surfaces, J. Math. Anal. Appl., 267 (2002), 746-759.

[9] R. FefFerman, A note on singular integrals, Proc. Amer. Math. Soc., 74 (1979), 266-270.

[10] L. GRAFAKOS AND A. STEFANOV, $L^{p}$ bounds for singular integrals and maximal singular integrals with rough kernels, Indiana Univ. Math. J., 47 (1998), 455-469.

[11] G. Hu, $L^{p}\left(\mathbb{R}^{n}\right)$ boundedness for the Marcinkiewicz integral, Approx. Theory Appl. (N. S.), 18, 4 (2002), 93-100.

[12] W. Kim, S. Wainger, J. Wright And S. Ziesler, Singular integrals and maximal functions associated to surfaces of revolution, Bull. London Math. Soc., 28 (1996), 291-296.

[13] S. LU, Y. PAN AND D. YANG, Rough singular integrals associated to surfaces of revolution, Proc. Amer. Math. Soc., 129 (2001), 2931-2940.

[14] S. S ATO, Estimates for singular integrals along surfaces of revolution, arXiv:0809.3315v1 [math.CA], to appear in J. Aust. Math. Soc.

[15] S. SATO, Estimates for Littlewood-Paley functions and extrapolation, Integr. equ. oper. theory, 62 (2008), 429-440.

[16] E. M. SteIn, Harmonic Analysis: Real-Variable Methods, Orthogonality and Oscillatory Integrals, Princeton University Press, Princeton, NJ, 1993.

[17] T. Walsh, On the function of Marcinkiewicz, Studia Math., 44 (1972), 203-217.

[18] M. Weiss AND A. Zygmund, An example in the theory of singular integrals, Studia Math., 26 (1965), 101-111. 
